\title{
Correction to: Intensity-dependent site amplification factors for Vrancea intermediate-depth earthquakes
}

\author{
Florin Pavel ${ }^{1} \cdot$ Radu Vacareanu $^{1} \cdot$ Kyriazis Pitilakis $^{2}$
}

Published online: 29 January 2019

(c) Springer Nature B.V. 2019

\section{Correction to: Bulletin of Earthquake Engineering https://doi.org/10.1007/s10518-019-00563-x}

Co-author name typo-name to be read as "Kyriazis Pitilakis" instead of "Kyriazis Pitiliakis".

The original article can be found online at https://doi.org/10.1007/s10518-019-00563-x.

\section{Florin Pavel}

florin.pavel@utcb.ro

1 Seismic Risk Assessment Research Centre, Technical University of Civil Engineering Bucharest, Bd. Lacul Tei, 122-124, Bucharest, Romania

2 Laboratory of Soil Mechanics, Foundations and Geotechnical Earthquake Engineering, Aristotle University of Thessaloniki, P.O.B. 424, 54124 Thessaloniki, Greece 